\title{
Sulphuric acid plant optimization and troubleshooting
}

\author{
by J. Hanekom
}

\section{Synopsis}

In an ideal world in which sulphuric acid plant operators could have anything they wish for, many would request an acid plant that never experiences corrosion, never has gas leaks, and never needs catalyst screening. And yet that is not the reality. All sulphuric acid plant operators experience acid mist carryover from sulphuric acid towers at some stage. If this is not detected and corrected quickly, extensive damage can be caused to downstream equipment. Not all mist carryover issues are related to poorly performing mist eliminators. This paper presents a review of the entire tower as a unit and discusses how process conditions, packing, acid distribution, mechanical factors, or mist eliminators affect the performance of the tower, as well as early detection and troubleshooting tools and methods.

\section{Keywords}

acid mist carryover, process conditions, packing, acid distribution, mechanical factors, mist eliminators.

\section{Introduction}

Unfortunately, there is no 'silver bullet' to optimize overall performance of a sulphuric acid plant. Plant equipment and operation must be viewed holistically to effectively integrate improvements to sustain efficient operation and profitability. This paper illustrates how tower and plant performance can be improved by an integrated approach that addresses both tower gas/acid distribution and mist elimination.

\section{Tower design - acid distribution and packing}

Proper dry tower design, maintenance, and operation impact overall plant performance and economics. Running the dry tower outside design conditions can lead to mist carryover into the blower and excessive acid carryover in the plant, resulting in corrosion, crusting of catalyst beds, and excessive acid in areas where it should not be present.

When designing a tower, it is therefore important to consider the following aspects of tower design:

Acid distribution

- Uniform and accurate acid distribution
- Limiting mist generation

- Wetting the walls

$>$ Gas distribution

- Gas velocity

- Optimum inlet gas nozzle and packing support design

> Liquid/gas contact

- Packing performance

- Gas and acid conditions

> The greater the open area in the tower, the less the pressure drop

An improvement of the drying tower (DT) acid distribution will reduce submicrometre acid mist formation. Figure 1 shows the effect of water vapour slipping past the DT as measured by the exit dry tower water dew point. This water vapour eventually combines with $\mathrm{SO}_{3}$ in the process gas, resulting in sulphuric acid vapour entering the inter-pass absorption tower (IPAT). Normal dew point temperature is less than $-40^{\circ} \mathrm{C}$; however, well-performing dry towers have much lower dew points. This can be a low as 50 to $-60^{\circ} \mathrm{C}$. The higher the dry tower dew point, the higher the inlet acid vapour content entering the IPAT and the higher the potential for acid mist formation once the gas enters the IPAT and cools below the sulphuric acid dew point.

The amount of sub-micrometre acid mist formed in the IPAT versus the amount of acid vapour condensing on wetted packing surfaces depends on the amount of acid vapour entering the IPAT, the concentration of nucleating agents in the gas (e.g. very fine dust particles from air or from ash resulting from sulphur burning) and fine particles from upstream metallurgical process, along with how the IPAT is designed and operated.

* Sulphur EMEA, MECS, South Africa.

(c) The Southern African Institute of Mining and Metallurgy, 2017. ISSN 2225-6253. This paper was first presented at the $6^{\text {th }}$ Sulphuric Acid 2017 Conference', 9-12 May 2017, Southern Sun Cape Sun, Cape Town. 


\section{Sulphuric acid plant optimization and troubleshooting}

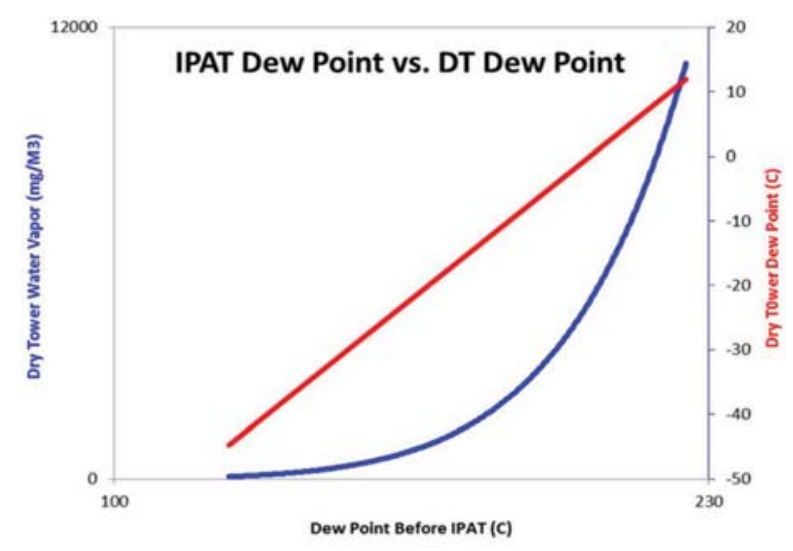

Figure 1-Effect of water vapour slipping past the dry tower

Improved mist elimination in the DT also helps reduce the acid vapour level at the inlet to the IPAT, since any acid mist reaching the downstream sulphur burner will decompose to $\mathrm{H}_{2} \mathrm{O}$ and $\mathrm{SO}_{3}$ and ultimately result in more acid vapour at the inlet to the IPAT.

On metallurgical acid plants the DT are often blamed for poorly performing upstream wet electrostatic precipitators (WESPs) often found in these plants. Sub-micrometre mist from WESP will pass through the drying tower and accumulate in the blower. The WESP sight glasses should always be optically clear.

\section{Tower design}

When designing an acid tower, it is imperative to keep the following in mind:

1. Good absorption of $\mathrm{SO}_{3}$ (absorbing towers) or $\mathrm{H}_{2} \mathrm{O}$ (drying tower) $=$ Uniform distribution

2. Low mist generation (saturation or overloading of mist eliminators)

$=$ No droplet carryover

3. Safe and reliable operation / maintenance = Easy access, no sulphate build-up, no plugging

4. Acid quality $=>$ low Fe content = Steel with low corrosion rates (Figure $2 \mathrm{a}$ ).

Uniform acid distribution is achieved by even irrigation of the packing both in the centre and near the walls, and of an equal flow per pour point (Figure 2b).

Droplet carryover can be avoided if the acid is discharged slowly, just under the packing without decreasing the tower open cross-section.

Flat packing support grids, such as the ZeCor ${ }^{\circledR}$ packing support grids, ensure equal packing thickness and equal gas distribution, and require no maintenance. The open area is more than $80 \%$ and the packing (random Intalox saddles) is installed directly on top of the grid. No grid blocks or crosspartition rings are required. ZeCor ${ }^{\circledR}$ packing support grids are easy to install and are supplied in easy-to-handle sections.

\section{Tower dew points as an early indicator of potential issues}

Dew point is defined as the temperature at which water in a gas condenses. The dew point for sulphuric acid plants is in

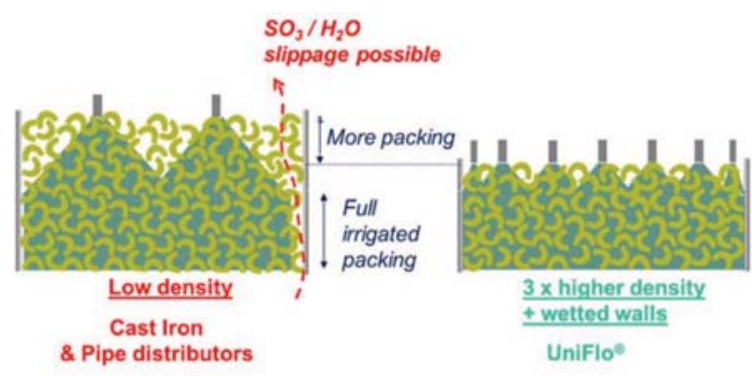

Figure 2a-Difference between low and high-density irrigation acid distributor

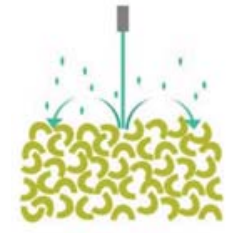

Splashing

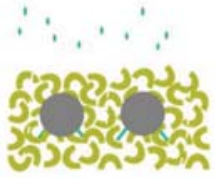

High gas velocity

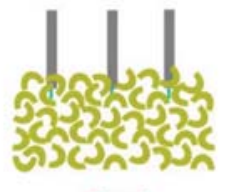

Good
Figure $2 \mathrm{~b}-$ Acid droplets above the ceramic packing

fact the point at which the first droplet of sulphuric acid condenses. However, the quantity is so small that it is invisible to the naked eye. An effective way for sulphuric acid plant operators to obtain accurate readings of the dew point is to use a vacuum pump to take measurements at the outlet of the dry tower if it is a suction tower. Dew-point measurement is an early detection method for any potential issues.

The $\mathrm{H}_{2} \mathrm{O}$ volume is 30 times that of $\mathrm{H}_{2} \mathrm{SO}_{4}$, making the water dew point visible first. For example:

Vapour pressure over $96 \% \mathrm{H}_{2} \mathrm{SO}_{4}$ at $65^{\circ} \mathrm{C}$ (typical DT operating point) $\mathrm{mmHg}$

$\begin{array}{ll}-\mathrm{H}_{2} \mathrm{O} & 0.02 \\ -\mathrm{H}_{2} \mathrm{SO}_{4} & 0.0007 \\ -\mathrm{SO}_{3} & 0.000002\end{array}$

The dew point matters because it affects drying tower efficiency, a crucial factor in plant optimization and one that has an impact on the life of a plant. As mentioned above, any moisture in the process gas will increase the dew point temperature before the IPAT. This will also increase the risk of acid condensation in economizers and in the converter during long hot shutdowns, increasing corrosion and damage to catalyst structure.

\section{The impact of mist eliminators on tower performance}

Tower performance is also affected by the choice of mist eliminator. Many different mist eliminator options are available in the market. They all intend to capture submicrometre liquid and soluble mists. However, they don't all function in the same way. Three mechanisms are used to capture mist-impaction, interception, and diffusion. MECS products use all three of these mechanisms - the impaction mechanism with the help of mesh pads, the interception mechanism with a combination of mesh pads and glass fibre, or the diffusion mechanism with the help of fibre beds to collect mist effectively. 


\section{Sulphuric acid plant optimization and troubleshooting}

Fibre bed collection intercepts particles ranging in size from $<1 \mu \mathrm{m}$ to larger particles $>3 \mu \mathrm{m}$, trapping them in the fibre bed as shown in Figure 3.

The focus of this paper will be on diffusion bed mist eliminators, which are predominantly used in IPAT and final absorption towers (FAT) in modern acid plants. Some plant still uses impaction/interception-type mist eliminators in the FAT

Diffusion bed mist eliminators are produced by wrapping glass fibre (in rope form) around an inner cage of metal wire or by compressing bulk glass fibre between two metal cages. The commonly used diffusion bed mist eliminators are the ones where glass fibre rope is wrapped around an inner cage - ES-type mist eliminators.

Two methods are used for placing fibre roving onto a mist eliminator - angle wrap and parallel wrap. The positioning of the fibre has a significant impact on the efficiency of the mist eliminator, as demonstrated with the help of thermographic imaging (Figures 4 and 5). Angle-wrapped mist eliminators tend to allow less heat to escape than parallel-wrapped fibre beds.

Velometry testing of angle- and parallel-wrapped fibre bed mist eliminators also shows a difference in performance (Table I, Figures 6 and 7).

Whatever the type of mist eliminator chosen, it is normally easy to install, but not to remove. Maintenance must be carried out on site. It is therefore vital, at installation, that enough space is planned for maintenance and parts replacement.

Although mist eliminators are relatively simple devices, it is important that they are installed properly. Many factors will affect the efficiency of a mist eliminator:

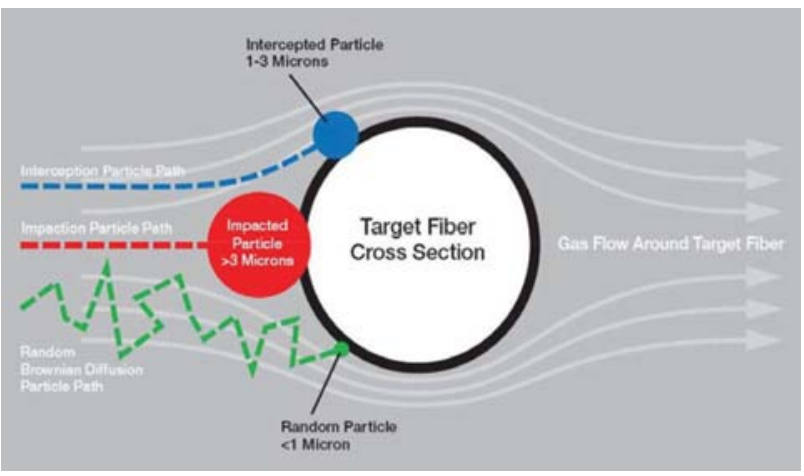

Figure 3-Fibre bed collection

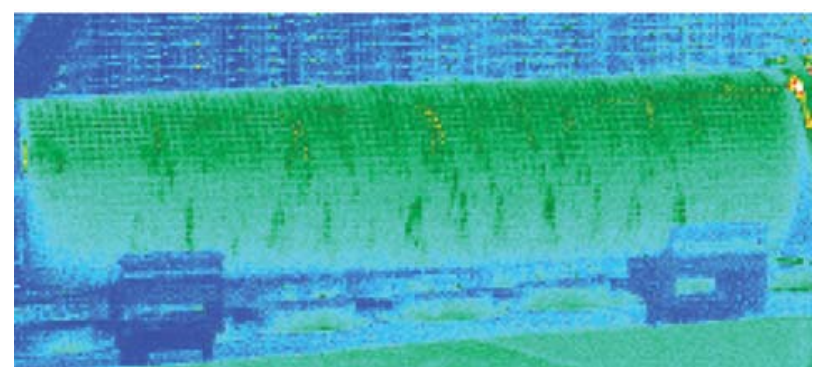

Figure 4-MECS ES angle-wrapped mist eliminator

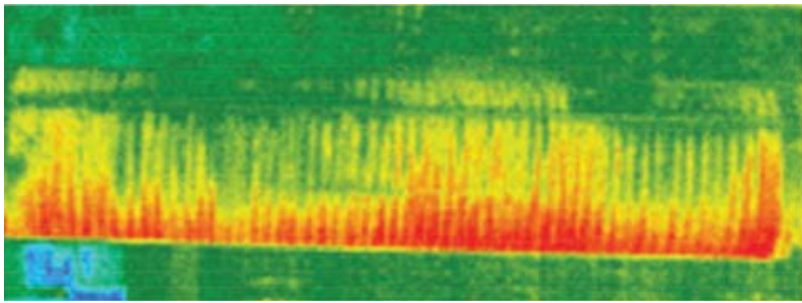

Figure 5-A parallel-wrapped mist eliminator

Table I

Results of velometry tests (ft/min)

\begin{tabular}{|l|c|c|c|}
\hline Item & Test Vb & Max. Vb & Min. Vb \\
\hline Standard packed (angle-wrapped) ES & 30 & 102 & 1 \\
Hand-packed (parallel-wrapped) ES & 30 & 685 & 4 \\
\hline
\end{tabular}

Velometry Standard Packed ES
Test $\mathrm{Vb}=30 \mathrm{fpm}, \operatorname{Max} V \mathrm{~b}=102 \mathrm{fpm}, \operatorname{Min} V \mathrm{~b}=1 \mathrm{fpm}$

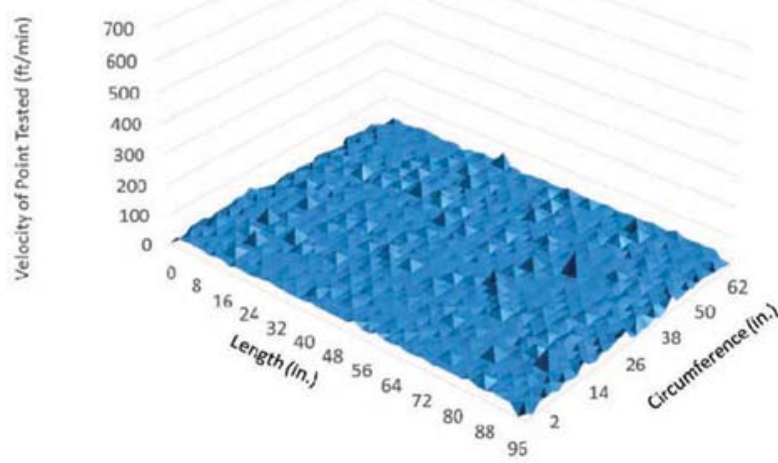

Figure 6-Velometry graph of an angle-wrapped mist eliminator

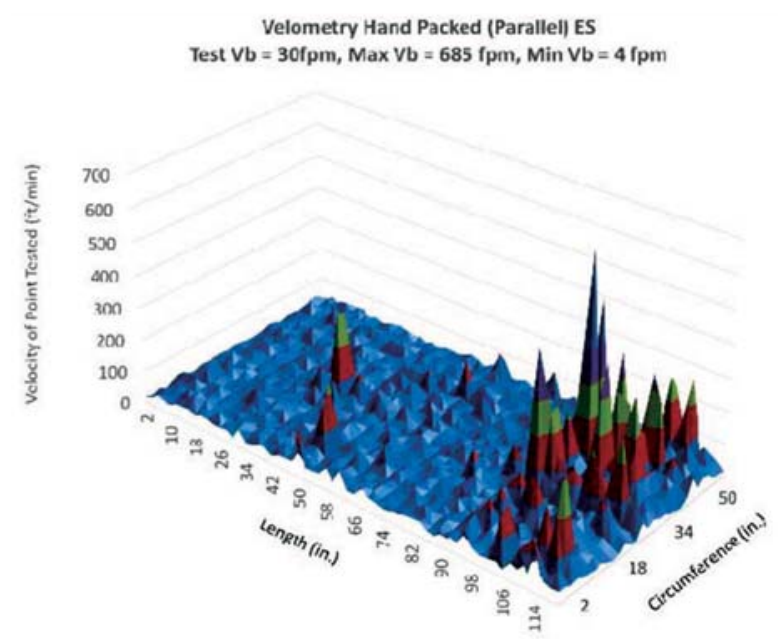

Figure 7-Velometry graph of a parallel wrapped mist eliminator

> Orientation of the mist eliminator - hanging or standing

$>$ Type of gaskets used 


\section{Sulphuric acid plant optimization and troubleshooting}

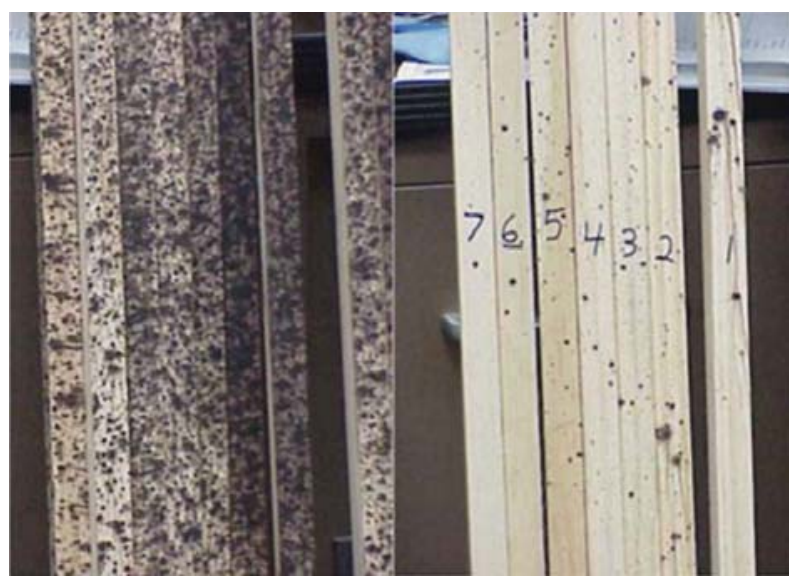

Figure 8-Dry tower stick test, before (left) and after (right)

> Is it installed on a pedestal or directly on the tube sheet?

$>$ Are the correct flange bolts used and are they torqued properly?

- Are seal pots or seal pipe used?

- Are seal pots filled up with acid before start-up?

\section{Troubleshooting: a systematic approach}

Preventing high acid mist carryover requires an understanding of its possible root causes. This involves a good knowledge of the plant design, an insight into the plant maintenance history (e.g. have there been tower distribution problems in the past?), a familiarity with the functioning of mist eliminators, plans for dealing with expected mist, and awareness of what constitutes a problem symptom.

\section{Problem symptoms}

These may include an abnormal drop in pressure, reentrainment, 'drip acid', stack opacity e.g. EPA method 9, and measurements that show high exit loading. Downstream systems such as high stack opacity, high EPA 8 emissions, or a charred stick often have the same root cause $\left(\mathrm{SO}_{3} / \mathrm{H}_{2} \mathrm{SO}_{4}\right.$ vapour) or can be due to very specific causes:

\section{What to avoid}

Although it is possible to run a plant with partially blinded candles, i.e. a blocked mist eliminator, there is a substantial risk of damaging the cages. In the case of sulphur sublimation, the best approach is to shut down the plant and wash or replace the mist eliminator elements. Hanging elements should never be operated with a dP more than 680 mmWC (27 inWC).

Fouled packing results in sulphate accumulation in mist eliminators and an increase in operating pressure drop.

Sulphuric acid plant operators can deploy a range of testing and troubleshooting methods aimed at addressing a variety of root causes for problems. They can vary from plotting element pressure drop divided by the actual gas flow versus time, to acid vapour and acid mist stick tests, drip acid volumes and concentration, dry tower stick tests, the installation of viewports and, of course, physical inspections, though these require shutdowns and will lead to a loss of production unless the inspections are scheduled to coincide with planned turnarounds.

Several ways to identify the reason for acid mist carryover from acid towers are listed below. The most common fault-finding method is a stick test on the outlet of the tower (Figure 8). The condition of the stick after 30 seconds, 1 minute or 3 minutes gives a sound qualitative assessment of acid mist carryover.

\section{Summary of testing/troubleshooting methods}

> Pressure drop and flow rate history - plant records and while operating

- Stick test-while operating

> Drip acid measurements-while operating

> Physical inspection-during plant shutdown

> View ports - requires planning and shutdown to install

> Smoke test-primarily for checking leaks at gaskets, liquid seals, and tube sheet

> Tyndall beam-while operating - requires some finesse/practice

$>$ Water dew-point-while operating

> Acid dew-point - while operating - not commonly used (expensive equipment)

> MECS method 104-requires planning and hot shutdown to install sampling nozzles and/or full-bore 4-inch gate or ball valves-last resort if other troubleshooting methods do not identify root causes.

\section{Conclusion}

Improving the performance of an acid plant is not a simple matter. Equipment cannot be placed in a haphazard, piecemeal fashion. Rather, the entire acid plant must be viewed holistically and improvements need to be made in a way that consider the interplay of all the various unit operations. Acid mist emissions cannot be reduced by simply optimizing tower operation, nor by simply enhancing mist capture. Indeed, the operational performance, and ultimately, the profitability, of many sulphuric acid plants will be improved only by incorporating and maintaining efficient tower acid distribution and superior mist elimination. This holistic approach is likely to reduce maintenance costs, avoid loss of production, and reduce stack acid mist emissions. 